\title{
Menores niveles tisulares de la enzima convertidora de angiotensina I homóloga (ECA-2) y angiotensina-(1-9) están asociados a mayor remodelamiento de la pared aórtica de ratas hipertensas
}

\author{
María Paz Ocaranza', Jackeline Moya', Melissa Pinto', Nicolás Escudero', Francisco \\ Valenzuela', Manuel Varas', Iván Godoy¹, Mario Chiong², Sergio Lavandero², Jorge Jalil'1. \\ ${ }^{1}$ Laboratorio de Cardiología Molecular, Departamento de Enfermedades Cardiovasculares, \\ Escuela de Medicina. Pontificia Universidad Católica de Chile. \\ ${ }^{2}$ Centro FONDAP CEMC. Universidad de Chile.
}

Recibido el 14 de Diciembre de 2009, Aceptado el 15 de Febrero de 2010

Rev Chil Cardiol 2010; 29: 69-82

\section{Resumen}

Antecedentes: Recientemente hemos propuesto en un modelo experimental de infarto al miocardio una significativa interregulación entre los niveles de la enzima convertidora de angiotensina I (ECA) y su homóloga (ECA-2), junto con que angiotensina (Ang)-(1-9) más que Ang-(1-7) actuaría como un contrarregulador de Ang II. Sin embargo tal relación no se ha investigado en el remodelado aórtico hipertensivo.

Objetivo: Determinar la expresión de ECA y ECA-2, los niveles de Angs I, II, (1-7) y (1-9) y los parámetros de remodelado de la pared aórtica de ratas hipertensas.

Métodos: Ratas normotensas Lewis ( $n=18)$ fueron randomizadas a hipertensión (HTA) por sobrecarga de presión (modelo Goldblatt, GB, 2 riñones-1 pinzado, $n=9$ ). Ratas pseudo-operadas se usaron como controles ( $S, n=9)$. A las 6 semanas post cirugía, se determinó la masa cardíaca relativa (MCR) y la presión arterial sistólica (PAS). En la aorta torácica se determinó el grosor de la túnica media (GTM), área de la TM (ATM), niveles de mRNA de ECA y ECA-2, factor de crecimiento transformante tipo $\beta$ (TGF- $\beta$ ), inhibidor del activador de plasminógeno (PAl-1) y de la proteína quimioatractante de monocitos (MCP-1) por RT-PCR. La actividad y niveles proteicos de ECA y ECA-2 por fluorimetría y Western blot y los niveles de Angs I, II, (1-7) y (1-9) por HPLC y radioinmunoensayo.

Resultados: La MCR y la PAS aumentaron significativamente $(p<0,05)$ en el grupo GB respecto a su control $S$. Las ratas hipertensas mostraron un aumento significativo $(p<0.05)$ del GTM (18\%), ATM (31\%), niveles de mRNA de ECA (164\%), TGF- $\beta$ (105\%), PAl-1(51\%), MCP-1 (53\%) junto con mayor actividad (89\%), niveles proteicos de ECA (130\%) y Ang II (48\%). Esos efectos se asociaron a una significativa disminución del mRNA, los niveles proteicos y actividad de ECA-2 (- 55\%, $-41 \%$ y $54 \%$, respectivamente) y a menores niveles aórticos (-25\%) de Ang- (1-9), sin diferencias en los niveles de ang-(1-7).

Correspondencia: María Paz Ocaranza

División de Enfermedades Cardiovasculares.

Facultad de Medicina. Pontificia Universidad Católica de Chile.

Tel: +562-3543407, Fax: +562-6321924.

Correo Electrónico: mocaran@med.puc.cl 
Conclusión: Estos resultados fuertemente sugieren que en la hipertensión arterial experimental, el remodelado de la pared aórtica está asociado a una interacción entre ECA y ECA-2 y los niveles de Ang II y Ang-(1-9), pero no de Ang-(1-7).

\section{Lower tissue levels of homologous angiotensin I converting enzyme (ACE-2) and angiotensin 1-9 are associated to increased remodeling of the aortic wall of hypertensive rats.}

Background: In experimental models of myocardial infarction we have recently proposed a significant inter-regulation between levels of Angiotensin I converting enzyme (ACE) and its homologous, ACE2; in addition, we have proposed that Angiotensin 1-9 (Ang-(1-9)) rather than Ang-(1-7) counter regulates Ang II. These relations have not been investigated in hypertensive aortic wall remodeling.

Aim: To measure de expression of ACE and ACE-2, the aortic wall levels of Ang I, Ang II, Ang-(1-7) and Ang-(1-9), along with parameters of aortic wall remodeling in hypertensive rats.

Methods: 18 Lewis rats were randomized to Goldblatt (2 kidneys, 1 clamped) induced hypertension ( $n=9)$ or sham operation (controls, $n=9$ ). Six weeks after surgery, relative cardiac mass $(R C M)$, systolic blood pressure $(S B P)$, medial layer aortic wall thickness $(M L T)$ and $M L$ area $(M L A)$ were measured. The aortic wall levels of ACE and ACE-2, tissue growth factor $\beta$ (TGF- $\beta$ ), plasminogen activator inhibitor (PAI-1) and monocyte chemoattractant protein (MCP-1) were determined by RT-PCR. Activity and protein levels of ACE and ACE-2 were measured by fluorometry and Western Blot and ANG I, Ang II, Ang-(1-7) and Ang-(1-9) levels were determined using HPLC and radioimmunoassay.

Results: RCM and SBP increased significantly in hypertensive as opossed to sham operated rats. Hypertensive rats had a significant $(p<0.05)$ increase in MLT (18\%), MLA, (31\%), mRNA levels of ACE (164\%), TGF- $\beta(105 \%)$, PAI-1 (51\%) and MCP-1 (53\%). ACE and ACE-2 protein levels increased by 130 and $48 \%$ respectively $(p<0.05)$. All these effects were associated to a significant decrease in mRNA, protein levels and actiity of ACE-2 $(-55 \%,-41 \%$ and $-54 \%$, respectively, along with decreased aortic wall levels of Ang-(1-9) (-25\%). Levels of Ang 1-7 were not modified in hypertensive rats.

Conclusion: these results strongly suggest that the aortic wall remodeling following experimentally induced hypertension is associated to interaction between ACE and ACE-2 and aortic wall levels of Ang II and Ang-(1-9), but not with those of Ang-(1-7).

(Fondecyt 1070662/FONDAP 15010006)

Key words: Homologous Angiotensin I converting Enzyme, angiotensin-(1-9), renin-angiotensin system.

\section{Introducción}

Desde un punto de vista clínico-fisiopatológico la hipertensión (HTA) no sólo se manifiesta con aumento de las cifras de presión arterial (PA), sino que también con alteraciones estructurales y funcionales de órganos blancos, tales como corazón, arterias y riñón ${ }^{1}$. En los pacientes con HTA se describe una variedad de cambios estructurales y funcionales a nivel de arterias de resistencia. Inicialmente, estos 
Menores niveles tisulares de la enzima convertidora de angiotensina I homóloga (ECA-2) y angiotensina-(1-9) están...

cambios son adaptativos, pero posteriormente resultan ser maladaptativos. Este proceso llamado remodelamiento vascular (RMV) contribuye a la fisiopatología de las enfermedades vasculares ${ }^{2}$. A nivel macroscópico, el RMV hipertrófico se caracteriza por aumento en el grosor de la media y disminución del diámetro del lumen y por consiguiente un aumento de la razón media/lumen ${ }^{3}$. No está claro si un aumento en la PA o bien otros factores inician el proceso de RMV. Sin embargo, el endotelio sirve como sensor de factores humorales y hemodinámicos y modera las señales que actúan sobre las células musculares lisas (CML), que participan activamente en el proceso de RV ${ }^{4}$.

Además, el RMV se acompaña de hipertrofia e hiperplasia de las de células musculares lisas, alteraciones en las proteínas de la matriz extracelular (MEC) e inflamación con infiltración de macrófagos. Diversas moléculas producidas en la pared arterial podrían dar cuenta de los cambios en el RMV en la HTA tales como: 1) El factor de crecimiento transformante $\beta_{1}\left(\mathrm{TGF} \beta_{1}\right)$, regulador transcripcional de la síntesis de colágeno $\left.{ }^{5}, 2\right)$ la proteína quimioatractante de monocitos (MCP-1) que regula el reclutamiento de los monocitos a los sitios de inflamación ${ }^{6,7}$ y 3) el inhibidor del activador de plasminógeno tipo $1 \mathrm{PAl}-1$, un potente inhibidor de los activadores de plasminógeno y por lo tanto regulador de la fibrinólisis en la pared arterial ${ }^{8,9}$.

La mayor activación del sistema renina-angiotensina (SRA), específicamente de la vía clásica, con mayor actividad de la enzima convertidora de angiotensina I (ECA) y niveles elevados de angiotensina (Ang) II se han identificado como importantes determinantes de la etiología de la HTA como en los procesos fisiopatológicos de RMV y alteraciones en la vasodilatación de arterias de resistencia. La ECA y Ang II representan así uno de los principales blancos terapéuticos para el tratamiento actual de la HTA ${ }^{1}$. Recientemente, una vía paralela del SRA ha sido descubierta ${ }^{10,11}$ donde la ECA homóloga (ECA-2) emerge como un novedoso blanco terapéutico para el tratamiento de la HTA y de sus complicaciones.
La ECA-2 degrada Ang I a Ang-(1-9) y Ang II a Ang-(1-7), por lo tanto, antagoniza la acción de la $\mathrm{ECA}^{12,13}$ Además la ECA-2 no hidroliza bradicininas (BK) y su actividad no es inhibida por los inhibidores de la ECA $\left(\right.$ IECA,$\left.{ }^{10}\right)$.

Existen varios estudios que muestran el significado funcional de la ECA-2 en la patofisiología cardiovascular $^{14,15}$. Nuestros resultados muestran en un modelo de remodelamiento miocárdico tardío post infarto al miocardio (IAM) aumentos en la actividad de ECA y niveles de Ang II junto con una disminución de la actividad de ECA-2 y niveles de Ang-(1-9), cambios que en conjunto favorecen el desarrollo de fibrosis miocárdica e hipertrofia ventricular patológica en el área no infartada ${ }^{16,17}$. La inhibición de la ECA como el bloqueo del receptor de Ang II tipo 1 (RAT1) previnieron la disminución de la actividad de ECA-2 post-IAM, aumentaron significativamente los niveles de Ang-(1-9) y disminuyeron el RM en el área no infartada ${ }^{17,18}$. Específicamente hemos propuesto que Ang-(1-9) más que Ang-(1-7) actúa como un contraregulador de la Ang $\mathrm{II}^{14}$. En resumen, estos resultados sugieren una interregulación entre ECA y ECA-2 en el remodelado miocárdico post-IAM, además que la Ang II podría ser el estímulo determinante de la expresión cardíaca de la ECA-2, ya que la disminución de los niveles de Ang II o la prevención de su unión a los RAT1 aumentaron los niveles del mRNA para ECA- $2^{18}$. La interregulación entre ECA y ECA-2, y su relación con remodelamiento aórtico hipertensivo, no ha sido explorada por lo cual el objetivo de este estudio fue determinar la expresión de ECA y ECA-2, los niveles de Angs I, II, (1-7) y (1-9) y los parámetros de remodelado de la pared aórtica en ratas hipertensas

\section{Materiales y Métodos}

La presente investigación se realizó de acuerdo a la "Guía para el cuidado y uso de animales de laboratorio" publicado por el "National Health Institute" (NIH No 85-23, 1985) y fue aprobada por la Comisión de Investigación de la Facultad de Medicina 
de la Pontificia Universidad Católica de Chile.

\section{Modelo experimental de Hipertensión.}

Se utilizaron ratas normotensas Lewis (peso 150 $\pm 10 \mathrm{~g}$ ) las cuales fueron randomizadas a hipertensión experimental usando el modelo Goldblatt (Gb; $2 \mathrm{r}-1 \mathrm{p})^{19}$. Como controles (S) se usaron animales seudo operados. Todos los animales fueron mantenidos bajo condiciones controladas de luz y oscuridad y tuvieron libre acceso a agua y comida y fueron eutanasiados a las 6 semanas post cirugía.

\section{Determinación de la presión arterial.}

La presión arterial sistólica (PAS) se midió por el método pletismográfico en la cola de los animales bajo suave anestesia con éter etílico un vez por semana ${ }^{19}$.

\section{Evaluación de la masa cardíaca relativa (MCR).}

Se cuantificó por la relación entre la masa del ventrículo izquierdo (MVI) y el peso corporal ${ }^{19}$.

\section{Obtención de aorta.}

Los animales se anestesiaron con Ketamina (35mg/Kg peso) y Xilacina $(7 \mathrm{mg} / \mathrm{Kg}$ peso) vía IP y la aorta fue extraída y lavada exhaustivamente en suero fisiológico. Una parte del tejido se fijó en formalina al $10 \%$ y el resto se guardó a $-80^{\circ} \mathrm{C}$ hasta su procesamiento.

\section{Determinación de hipertrofia aórtica por morfo- metría}

Se usaron cortes de la aorta descendente de $5 \mu \mathrm{m}$ de grosor que fueron previamente fijados en formalina al $10 \%$ por $24 \mathrm{hrs}$, incluidos en parafina y teñidos con hematoxilina-eosina, para después ser examinados en un microscopio de luz acuerdo a lo descrito por Igase et al. ${ }^{20}$. Brevemente, las imágenes de las aortas fueron captadas mediante una cámara de video (Nikon) fijada a un microscopio (Nikon), y proyectadas en un monitor; mediante el uso del software de análisis Image J. Glóbulos rojos presentes en cada una de las imágenes sirvieron para fijar las dimen- siones. Se calculó y registró las áreas del lumen $(A L)$ y total (AT). El área de la túnica media (ATM) se obtuvo de la diferencia del AT y el AL de la aorta. El grosor de la túnica media (GTM) se definió como la región delimitada por la lámina elástica externa (LEE) y la lámina elástica interna (LEI).

\section{Niveles de de mRNA de ECA-2, ECA, MCP-1, PAI- 1 y TGF- $\beta$ en aorta}

Se siguió el procedimiento descrito por Ocaranza et $\mathrm{al}^{16}$. Brevemente, el RNA total del ápice del VI se aisló por el método del trizol y se cuantificó por espectroscopia a 260/280nm. El cDNA se obtuvo por transcripción reversa a partir de 1,5 $\mu \mathrm{g}$ de RNA total tratado con DNAsa. Los ensayos de PCR se realizaron usando los siguientes protocolos de amplificación y secuencias de partidores, ECA: 40 ciclos de denaturación a $94^{\circ} \mathrm{C}$ por $1 \mathrm{~min}$, hibridización a $62^{\circ} \mathrm{C}$ por 1 min y elongación a $72^{\circ} \mathrm{C}$ por 1 min. Como partidor sentido se usó: CAG-CTT-CAT-CAT-CCAGTT-CC 3' y antisentido: 5' CTA-GGA-AGA-GCAGCA-CCC-AC $3^{\prime \prime 16}$. ECA-2 38 ciclos de denaturación a $94^{\circ} \mathrm{C}$ por $1 \mathrm{~min}$, hibridización a $60^{\circ} \mathrm{C}$ por 1 min y elongación a $72^{\circ} \mathrm{C}$ por 1 min. Como partidor sentido se usó: 5' GTG-CAC-AAA-GGT-GAC-AATGG 3' y antisentido: 5'ATG-CGG-GGT-CAC-AGTATG-TT 3"16. TGF $\beta_{1} 33$ ciclos de denaturación a $94^{\circ} \mathrm{C}$ por 1 min, hibridización a $52^{\circ} \mathrm{C}$ por 1 min y elongación a $72^{\circ} \mathrm{C}$ por $1 \mathrm{~min}$. Como partidor sentido se usó 5'-AAGCCCTGTATTCCGTCTCC-3' y antisentido $5^{\prime}$ - C AA C G C C A T C TA T G A G A A A A C C - $3{ }^{\prime} 21$. PAl-1 33 ciclos de $1 \mathrm{~min}$. a $94^{\circ} \mathrm{C}, 0.5 \mathrm{~min}$. a $58^{\circ} \mathrm{C}$, 1 min. a $72^{\circ} \mathrm{C}$ y posteriormente $10 \mathrm{~min}$. a $72{ }^{\circ} \mathrm{C}$. Como partidor sentido se usó 5 '-ATGAGATCAGTACTG CGGACGCCATCTTTG-3' y partidor antisentido 5'GCA CGGAGATGGTGCTACCATCAGACTTGT- $3^{2}{ }^{21}$. MCP-1 38 ciclos de $1 \mathrm{~min}$. a $92^{\circ} \mathrm{C}, 1 \mathrm{~min}$ a $53^{\circ} \mathrm{C}, 1$ min a $72^{\circ} \mathrm{C}$ y posteriormente $10 \mathrm{~min}$ a $72{ }^{\circ} \mathrm{C}$. Las secuencias nucleotídicas de los partidores sentido y antisentido fueron 5'-CAGGTCTCTGTCACGCTTCT-3' y 5'-GTGCTTCAGGTGGTTGTGG3', respectivamente ${ }^{21}$.

La intensidad de las bandas se cuantificó por 
densitometría y se normalizó con respecto a la banda $18 \mathrm{~S}$ del RNA ribosomal.

\section{Niveles de ECA y ECA-2 en la pared aórtica}

Se utilizaron $30 \mu \mathrm{g}$ y $50 \mu \mathrm{g}$ de proteína total de aorta para la determinación de ECA y ECA-2, respectivamente. Los homogenizados de aorta se diluyeron en tampón reductor SDS $(50 \mathrm{mM}$ tris- $\mathrm{HCl}$, $\mathrm{pH}$ 6,8, $100 \mathrm{mM}$ DTT, 2\% SDS, 0,1\% azul de bromofenol, $10 \%$ glicerol) y se separaron por electroforesis en geles SDS-PAGE al $8 \%$. Las proteínas se transfirieron a membranas de nitrocelulosa de $0,2 \mu \mathrm{m}$ a $350 \mathrm{~mA}$ durante 1 hora. La transferencia de las proteínas se verificó por tinción de la nitrocelulosa con Rojo Ponceau. Posteriormente, las membranas se bloquearon en solución PBS-Leche descremada al $7 \%$ durante toda la noche con agitación a $4{ }^{\circ} \mathrm{C}$ y después de 3 lavados de 10 minutos con leche 0,5\% en PBS-Tween 20 0,05\%, se incubaron con el anticuerpo anti-ECA (dilución 1:3000) o antiECA-2 (1:5000) en leche $0.05 \%$ PBS-T $0.05 \%$ ) dejándose en agitación toda la noche a $4^{\circ} \mathrm{C}$. Después de 3 lavados por 10 minutos con PBS-Tween 20 0.05\% más leche $0.5 \%$, se agregó el anticuerpo secundario anti-conejo (Pierce) conjugado con peroxidasa en dilución 1:10000 y se incubó por 2 horas a temperatura ambiente. Después de 3 lavados se reveló con un sustrato quimioluminicente. La cuantificación de la intensidad de cada banda se analizó por densitométria mediante un scanner Hewlet-Packard y el software UN-SCAN-IT de análisis densitométrico.

\section{Actividad de ECA y ECA-2 en la pared aórtica}

La actividad de la ECA se determinó tal como lo describió Oliveri et $\mathrm{al}^{22}$ y se expresó en $\mathrm{U} / \mathrm{mg}$ proteina (1U: nmoles $\mathrm{HL} / \mathrm{min}$ ).

Para la medición de la actividad de ECA-2 se usó como sustrato el péptido 7-metil coumarina (Mca) -R-PP-G-F-S-A-F-K(Dnp)-OH_(R\&Dsystems), el cual posee un grupo apagador (Dnp) de la fluorescencia descrito por Jonhson y Ahn ${ }^{23}$. Brevemente, el ensayo de actividad enzimática se realizó en un volumen total de
$100 \mu \mathrm{L}$ de tampón de reacción en el cual se adicionaron $20 \mu \mathrm{L}$ de de plasma o $10 \mu \mathrm{L}$ de homogenizado de $\mathrm{VI}$, $10 \mu \mathrm{M}$ de sustrato, $3 \mathrm{mM}$ de enalapril y tampón de reacción (50 mM Tris- $\mathrm{HCl}, \mathrm{pH} 7,4,0,2 \mathrm{mM} \mathrm{NaCl})$. Como control se usó igual mezcla de reacción a la cual se le adicionó $10 \mathrm{mM}$ de EDTA. La mezcla se incubó a $37^{\circ} \mathrm{C}$ por 30 min y la reacción enzimática fue detenida calentando a $100^{\circ} \mathrm{C}$ por $5 \mathrm{~min}^{16}$.

Posteriormente las muestras se centrifugaron a $10.000 \mathrm{~g}$ por $10 \mathrm{~min}$. La actividad en aorta se expresó en $\mathrm{U}$ (pmoles de 7 metil coumarina/min)/mg proteina).

\section{Niveles de angiotensinas en la pared aórtica.}

Brevemente, las ratas se anestesiaron con ketamina (125 mg/kg) y xilazina $(12.5 \mathrm{mg} / \mathrm{kg}$ ) por vía i.p. La aorta se separó y se homogenizó en $5 \mathrm{~mL}$ de $4 \mathrm{M}$ de tiocianato de guanidinio (GTC). Los homogenizados fueron almacenados a $-80^{\circ} \mathrm{C}$ hasta ser extraídos en minicolumnas Sep-Pak C18. Las Angs fueron separadas por HPLC y cuantificadas por radioinmunoensayo (RIA) usando anticuerpos policlonales dirigido contra los extremos aminoterminales donado por el Dr DJ Campbell (St, Vincent's Institute of Medical Research, University of Melbourne, Fitzroy) ${ }^{16,24}$.

\section{Expresión de resultados y análisis estadístico}

Los datos obtenidos se expresaron como promedio \pm error estándar. Los grupos experimentales estuvieron constituidos por 9 animales. Para las comparaciones se usó análisis estadístico de prueba de t de Student. El análisis estadístico se realizó usando el programa estadístico SPSS 10.0. Un valor de $p<0,05$ fue considerado como estadísticamente significativo.

\section{Resultados}

\section{Presión arterial sistólica y masa cardíaca relativa.}

En respuesta al estímulo de sobrecarga de presión, el peso corporal no varió respecto a sus controles a las 6 semanas post cirugía. Sin embargo, la MCR y la PAS aumentaron significativamente (27 y 54\%, respectivamente) en los grupos GB respecto a sus controles $S$ (Tabla 1 ). 
M. P. Ocaranza, J. Moya, M. Pinto, N. Escudero, F. Valenzuela, M. Varas, el al.

Tabla 1. Parámetros hemodinámicos, peso corporal y masa cardíaca relativa.

\begin{tabular}{lcc}
\hline & S & GB \\
\hline $\mathrm{N}$ & 9 & 9 \\
Peso corporal $(\mathrm{g})$ & $250 \pm 7$ & $242 \pm 11$ \\
$\mathrm{MCR}(\mathrm{mg} \mathrm{VI} / \mathrm{MC})$ & $313 \pm 10$ & $396 \pm 18^{*}$ \\
PAS $(\mathrm{mm} \mathrm{Hg})$ & $105 \pm 3$ & $162 \pm 7^{\star}$ \\
\hline
\end{tabular}

Los resultados representan el promedio \pm error estándar. MC: masa corporal, PAS: presión arterial sistólica, MCR: masa cardiaca relativa, S: Sham; GB: Goldblatt. . Símbolos * $=p<0.05$ vs Sham.

\section{Hipertrofia vascular.}

La figura 1 muestra el AL, ATM, ATM/AL y el GTM de las aortas de los 2 grupos experimentales. El $A L$ no mostró diferencias entre las ratas $S$ y las
GB (figura 1E). Mientras que, el GTM (figura 1C), ATM (figura 1D) y ATM/AL (figura 1F) aumentaron un $30 \%, 31 \%$ y $36 \%$, respectivamente, en las aortas de las ratas hipertensas GB respecto al grupo control.

\section{A}

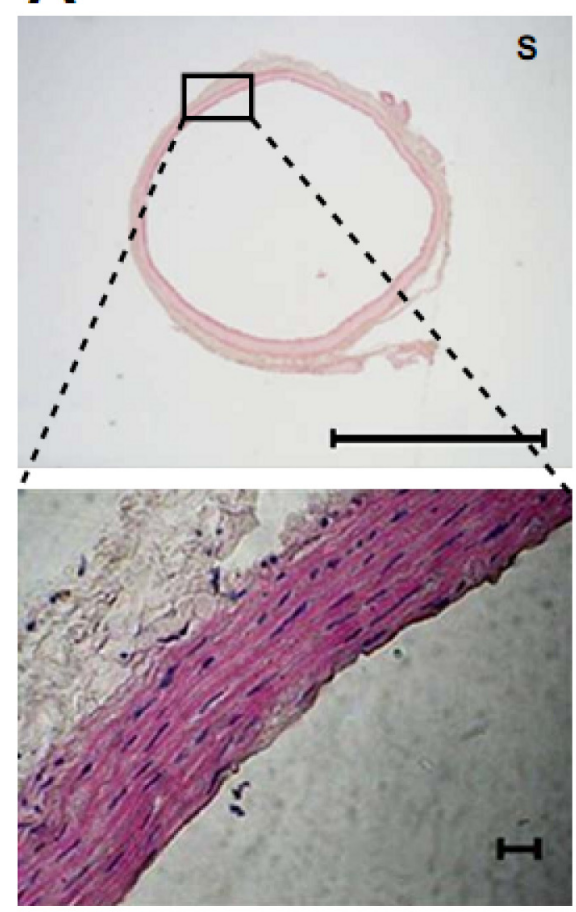

B

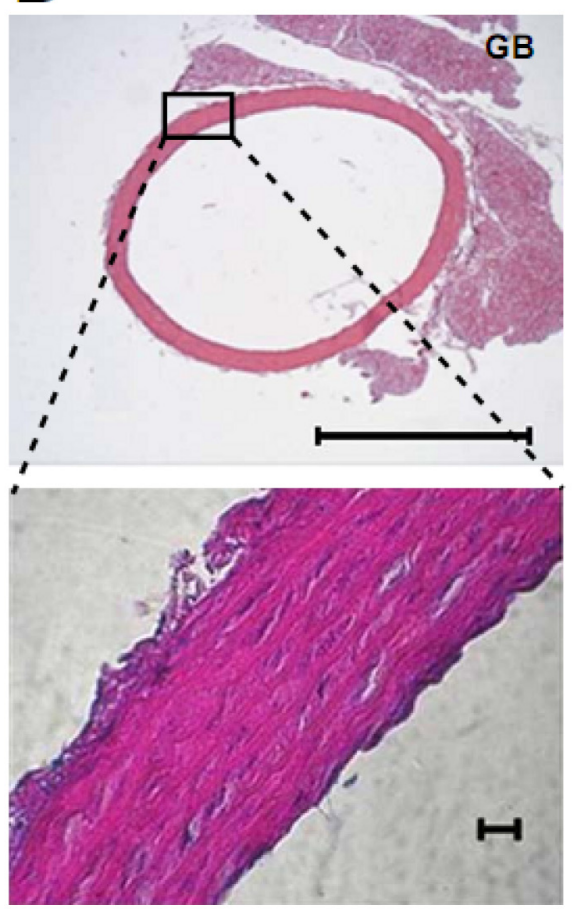

Figura 1. A) Muestras representativas de la inmunotinción de cortes de aorta torácica de ratas sham (S). Barra superior= $1 \mathrm{~mm}$, barra inferior $=25 \mathrm{~mm}$. B) Muestras representativas de la inmunotinción de cortes de aorta torácica de ratas hipertensas Goldblatt (GB). Barra superior $=1 \mathrm{~mm}$, barra inferior $=25 \mu \mathrm{m}$. 

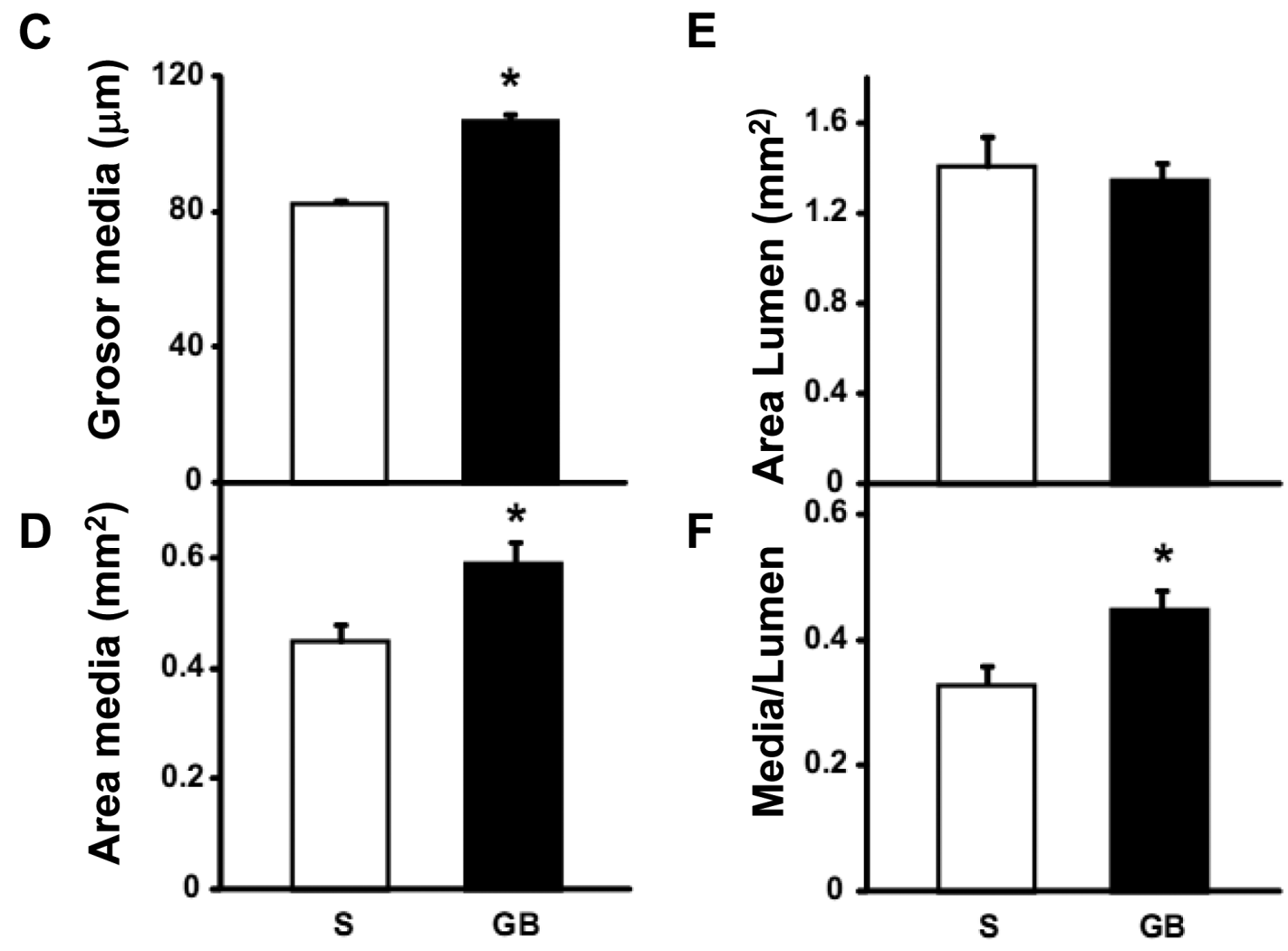

Figura 1: C) Cuantificación del grosor de la media de ratas Sham (S, barra blanca) e hipertensas (GB, barra negra). D) Cuantificación del área de la media de ratas Sham (S, barra blanca) e hipertensas (GB, barra negra). E) Cuantificación del área del lumen de ratas Sham (S, barra blanca) e hipertensas (GB, barra negra). F) Razón área media del lumen de ratas Sham (S, barra blanca) e hipertensas (GB, barra negra). Los valores representan el promedio \pm error estándar. * $=$ $p<0.05$ vs $S$.

3. Niveles de mRNA, proteína y actividad de ECA y ECA2 en la pared aórtica.

En ratas hipertensas los niveles de mRNA para ECA aumentaron significativamente respecto a su control $(2,2 \pm 0,5$ vs $1 \pm 0,20, p=0,02$, respectivamente, figura 2A). En cambio, los niveles de mRNA para ECA-2 disminuyeron significativamente en las ratas GB vs $S(0,45 \pm 0,08$ vs $1 \pm 0,17, p=0,03$, respectivamente, figura $2 \mathrm{~A}$ ). Esta interre-gulación a nivel del mRNA también se encontró a nivel de la expresión proteica de ECA y ECA-2 donde se observó que los niveles proteicos de ECA fueron significativamente mayores en las $\mathrm{GB}$ respecto a su control $(2,3 \pm 0,5$ vs $1 \pm 0,20, p=0,01$, respectivamente, figura 2B). Mientras que los niveles de ECA-2 disminuyeron significativamente un $45 \%$ en las ratas hipertensas (figura 2B).

La actividad enzimática de ECA en la pared aórtica mostró un aumento de un $89 \%$ (155 \pm 9 vs $82 \pm 12$, figura $2 \mathrm{C}$ ) en las ratas $\mathrm{GB}$, mientras que la actividad de la ECA-2 disminuyó significativamente un $54 \%(0.12 \pm 0.03$ vs $0.26 \pm 0.04)$ respecto a las ratas controles (figura 2C). 

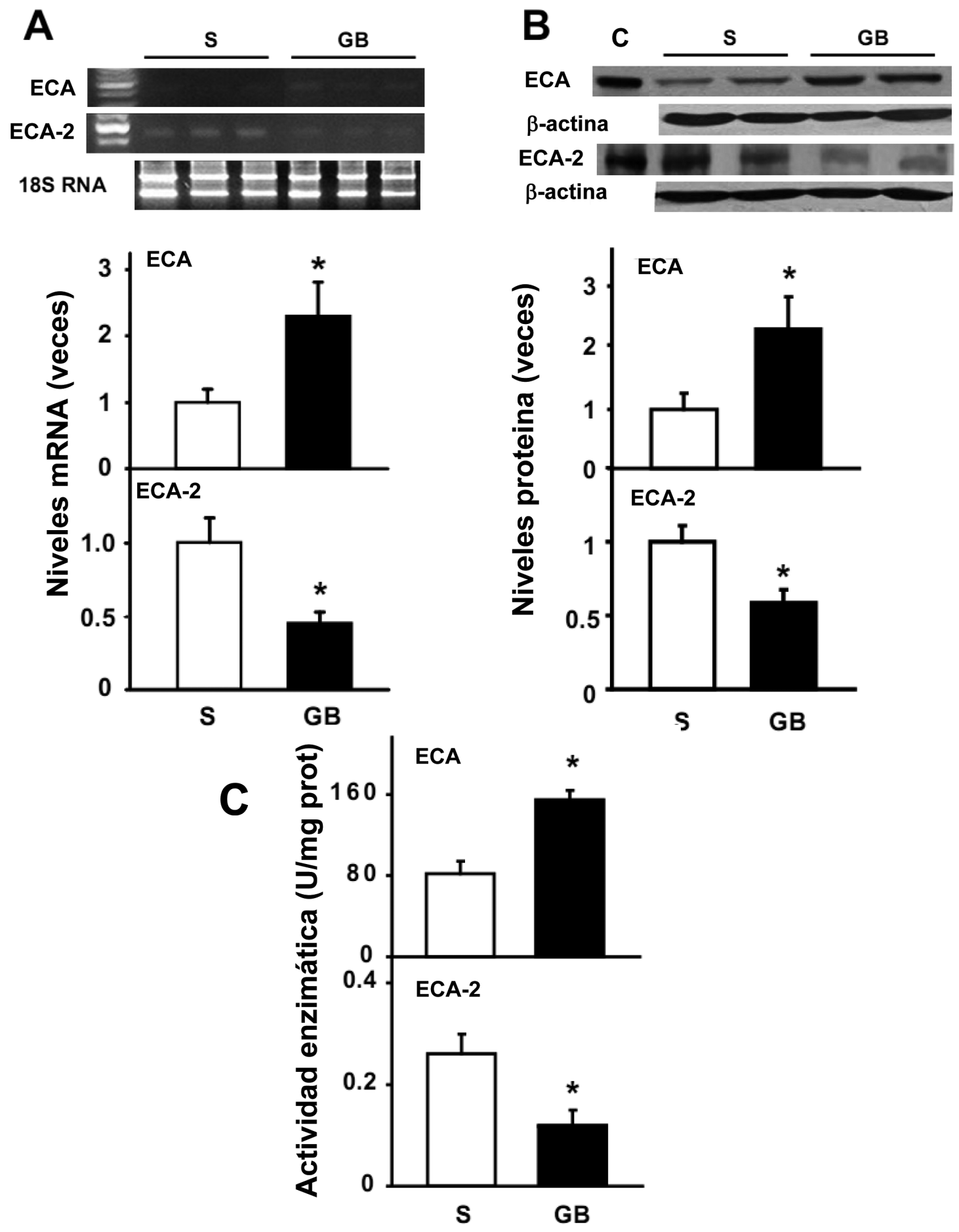

Figura 2. Niveles de mRNA, proteína y actividad de ECA y ECA-2 en la pared aórtica. A) Niveles de mRNA de ECA y ECA-2 respecto a la banda $18 \mathrm{~S}$ del RNA en la pared aórtica. B) Niveles de la proteína ECA y ECA-2 respecto a los niveles de la proteína $\beta$-actina en la pared aórtica. C) Actividad de ECA (U: nmoles e histidil-leucina/mg proteína) y ECA-2 (U: nmoles de 7-metixocoumarina/mg proteína) en la pared aórtica. Los valores representan el promedio \pm error estándar. Abreviaciones: S: ratas sham, barra blanca, GB: ratas goldblatt. Barra negra: * $=p<0.05$ vs $S$ 
Menores niveles tisulares de la enzima convertidora de angiotensina I homóloga (ECA-2) y angiotensina-(1-9) están...

\section{Niveles de angiotensinas en la pared aórtica}

Los niveles de Ang II y la razón Ang II/ Ang I fueron significativamente mayores en la pared aórtica de ratas hipertensas respecto a sus controles $(89,0 \pm 2,8$ vs $60,3 \pm 3, p<0.04$ y $5,7 \pm 0,3$ vs $3,7 \pm 0,3$, respectivamente, tabla 2). Mientras que los niveles aórticos de Ang-(1-9) y la razón Ang-(1-9)/Ang I disminuyeron significativamente en las ratas hipertensas en relación a las ratas normotensas $(13,9 \pm 0.5$ vs $18,5 \pm 1,3, p<0.03$ y $0,78 \pm 0$ vs $1,1 \pm 0,1$, respectiva- mente, tabla 2). Sin embargo, los niveles e Angs I y (1-7) fueron similares en ambos grupos experimentales (tabla 2).

5. Niveles de mRNA de TGF- $\beta$, PAl-1 y MCP-1.

El estímulo hipertensivo aumentó significativamente los niveles de mRNA de TGF- $\beta$ ( 2.07 \pm 0.41 vs $1 \pm 0.16$, figuras $3 \mathrm{~A}$ y $3 \mathrm{~B})$, PAl- $1(1.51 \pm 0.19$ vs $1 \pm 0.14$, figuras $3 \mathrm{~A}$ y $3 \mathrm{C})$ y MCP-1 $(1,53 \pm 0,14$ vs $1 \pm 0,16, p<0,05$, figuras $3 A$ y $3 D$ )

Tabla 2. Niveles de angiotensinas en la pared aórtica

\begin{tabular}{ccc}
\hline Parámetros & $\mathbf{S}$ & $\mathbf{G B}$ \\
\hline Ang I (fmol/mg) & $\mathbf{9}$ & $\mathbf{9}$ \\
\hline Ang II (fmol/mg) & $17.0 \pm 1.0$ & $17.5 \pm 1.2$ \\
Ang-(1-7) (fmol/mg) & $10.4 \pm 1.0$ & $89.0 \pm 2.8^{*}$ \\
Ang-(1-9) (fmol/mg) & $18.5 \pm 1.3$ & $10.6 \pm 1.3$ \\
Ang-(1-7)/Ang II & $0.19 \pm 0.02$ & $13.9 \pm 0.7^{*}$ \\
Ang-(1-9)/ Ang I & $1.1 \pm 0.1$ & $0.19 \pm 0.05$ \\
Ang II/ Ang I & $3.7 \pm 0.3$ & $0.78 \pm 0^{*}$ \\
\hline
\end{tabular}

Los valores representan el promedio \pm error estándar. Abreviaciones: S: sham; GB: Goldblatt.

$\mathrm{N}$ : número de animales. $\mathrm{p}<0.05$ vs $\mathrm{S}$

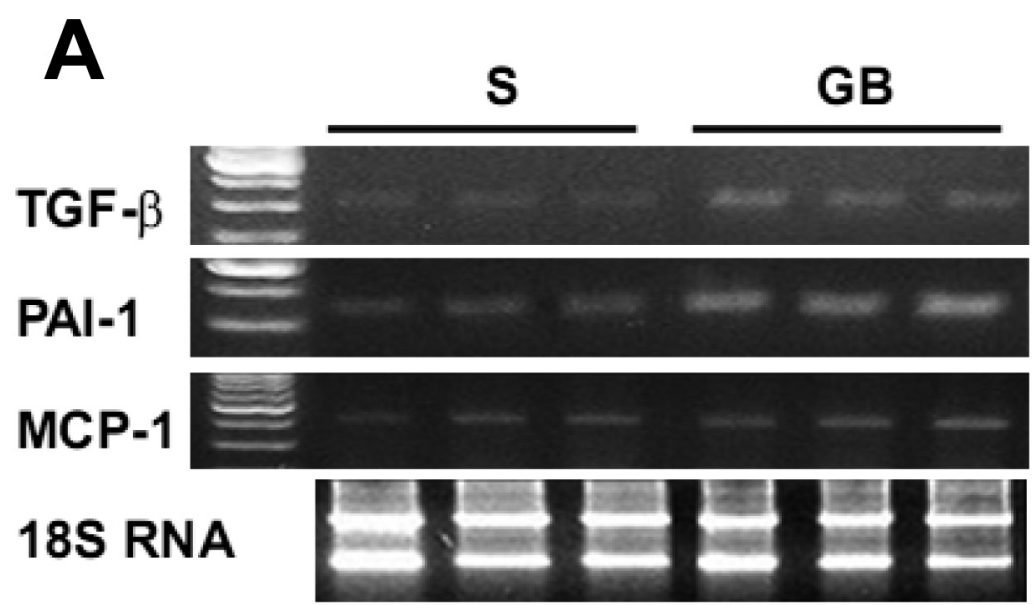




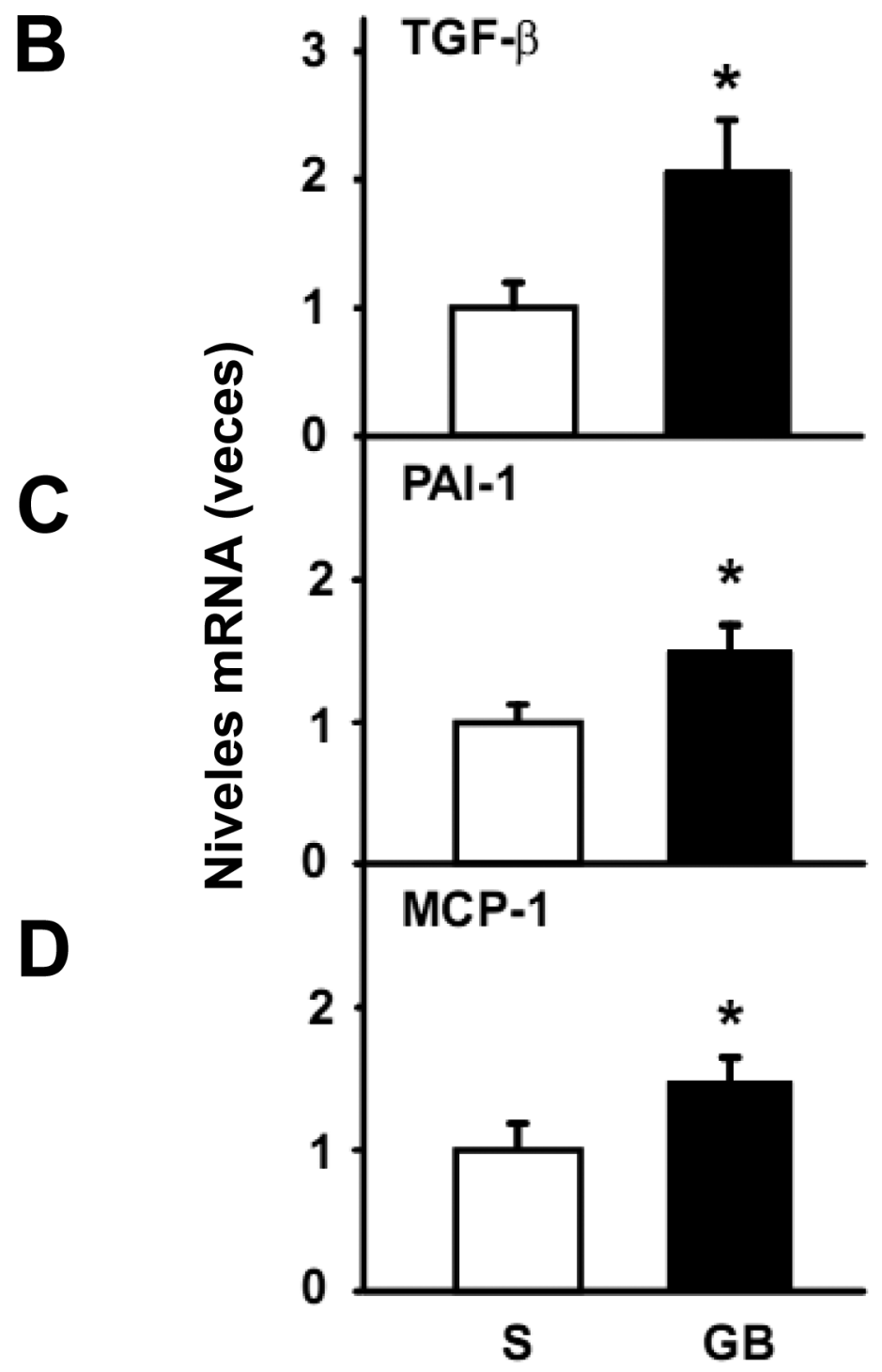

Figura 3. Niveles de mRNA de genes de remodelamiento de la pared aórtica. A) Productos de RT-PCR de TGF$\beta$, PAI-1 y MCP-1, B) Cuantificación de los niveles de mRNA de TGF- $\beta$ respecto a la banda 18S del RNA. B) Niveles de mRNA de PAl-1 respecto a la banda 18S del RNA y, C) Niveles de mRNA de MCP-1 respecto a la banda $18 \mathrm{~S}$ del RNA. Los valores representan el promedio \pm SEM y se expresan como veces respecto al control sham. ${ }^{*}=p<0.05$ vs $S$. Abreviaciones: TGF- $\beta$ : factor de transformación fibroblástica tipo 1;:PAI-1: inhibidor del activador de plasminógeno tipo 1 y MCP-1: proteína quimioatractante de monocitos.

\section{Discusión}

Nuestros resultados muestran que: 1) La HTA experimental por sobrecarga de presión aumentó la MRC, sin cambios en el peso corporal. 2) En la pared aórtica de ratas hipertensas, los niveles génicos, proteicos y la actividad de la ECA fueron significativamente mayores, mientras que para ECA-2 fueron significativamente menores respecto a las ratas normotensas. Estos resultados se asociaron a 
3) mayores niveles aórticos de Ang II y menores de Ang-(1-9) sin cambios en los niveles de Ang I y (1-7) y 4) mayor remodelamiento molecular de la pared aórtica medido por los niveles de mRNA de TGF- $\beta$, PAI-1 y MCP-1.

Es conocido que varios componentes del SRA están involucrados en la formación de la neoíntima después del daño al endotelio vascular. Al respecto, Rakugi et al. ${ }^{25}$ mostraron que el daño del endotelio vascular resulta de la activación de la ECA y que la disminución de la presión arterial con drogas que bloquean el SRA tales como inhibidores de la ECA o antagonistas del RAT1 de Ang II revierten el remodelamiento del vaso ${ }^{26}$.

La vía paralela del SRA ${ }^{10,11}$, específicamente la ECA-2 y la Ang-(1-7) han emergido como novedosos blancos terapéuticos para el tratamiento de la HTA y de sus complicaciones. La ECA-2 no sólo participa en la metabolización de Angs I y II y produce Angs-(1-9) y (1-7), respectivamente, sino que también hidroliza otros péptidos vasoactivos como apelina-13, conexinas, des-Arg' ${ }^{9}$-bradikinina, neurotensina, y péptidos opiodes, tales como dinorfina $A(1-13)^{10}$. Estos productos presentan una variedad de funciones por lo que la ECA-2 puede tener un rol en inflamación, neurotransmisión y funciones cardiovasculares. Aunque la ECA-2 hidroliza varios sustratos, la producción de Ang-(1-7) parece tener uno de los roles mas importante a nivel cardiovascular ${ }^{27}$.

La Ang-(1-7) ha mostrado ser un importante regulador de la función cardiovascular y renal promoviendo la vasodilatación, apoptosis y efecto antiproliferativo ${ }^{28}$. Este péptido, a través de su receptor, el producto del oncogén Mas $\left(\mathrm{MAS}^{29}\right)$ estimularía la óxido nítrico sintetasa (NOS) y contrarrestaría las acciones de Ang II. El efecto de la Ang-(1-7) también podría ser por unión al RAT2, aumentando la unión de bradikinina a su receptor $B_{2}{ }^{30}$. Ang-(1-7) se degrada a péptidos inactivos por acción de la ECA. Por lo tanto, la inhibición de la ECA podría aumentar los niveles de Ang-(17) y simultáneamente disminuir los de Ang II. Ya que
Ang-(1-7) es un potente péptido vasodilatador, su acción contrarrestaría el efecto vasopresor de Ang II. Por lo tanto, la ECA-2 intervendría en la mantención del tono vascular, contrarregulando los efectos derivados de la ECA ${ }^{31}$.

Las evidencias que se han ido acumulando desde el descubrimiento de la ECA-2 muestran que su mRNA se expresa en arterias de conducción como aorta y carótidas de ratas espontáneamente hipertensas ${ }^{20}$, arteriolas y en el vasa vasorum de muchos órganos ${ }^{10,32}$. Además la ECA-2 se localiza preferentemente en células endoteliales y musculares lisas vasculares $(\mathrm{CMLV})^{10,20}$. El efecto de la ECA-2 en la formación de la neoíntima no se ha estudiado. Sin embargo, la administración de Ang-(1-7) después de daño catéter balón en la arteria carótida disminuyó la formación de la neoíntima ${ }^{33}$. Probablemente este efecto fue mediado por la inhibición de la proliferación de CMLV ${ }^{34}$.

Nuestros resultados muestran que la pared aórtica de ratas hipertensas presentan mayores niveles de mRNA, proteína y actividad de la ECA $(130 \%, 120 \%$ y $89 \%$, respectivamente) y de Ang II (47\%) al compararlas con ratas normotensas. Mientras que, los niveles de mRNA, proteína y actividad de ECA-2 (-55\%, $-45 \%$ y $54 \%$, respectivamente) y de Ang-(1-9) (-25\%) fueron significativamente menores, sin diferencias los niveles de Ang I y (1-7). Estos resultados se asociaron a mayor grosor de la pared aórtica (29\%), mayor área de la media (31\%) y mayor razón lumen/media (36\%), también como a mayores niveles de mRNA de genes de RMV como TGF- $\beta 1$, PAl-1 y MCP-1. Estos resultados fuertemente sugieren que el RMV no sólo depende de los niveles aórticos de ECA y Ang II sino que también depende de los niveles aórticos del eje ECA-2-Ang-(1-9). Al respecto, estudios previos de nuestro grupo ${ }^{35}$ han mostrado en la pared aórtica de ratas normotensas con niveles genéticamente elevados de ECA y ANG II mayores niveles de mRNA y proteína de ECA (134\% y $60 \%$, respectivamente) y menores niveles de ECA-2 (-73\% and $-74 \%$, 
respectivamente, $\quad p<0.05)$ como también menores niveles de Ang-(1-9) $(-21 \% ; p<0.05)$, sin diferencias en las Angs I y (1-7). Estos resultados se asociaron con mayor grosor de la pared aórtica (15\%), área de la media $(10 \%)$ y mayores niveles de mRNA de TGF- $\beta 1$, PAl-1 and MCP- ${ }^{35}$. Dado que la Ang II es hidrolizada por ECA2 con una alta eficiencia catalítica, estos resultados sugieren que la ECA2 podría participar en los mecanismos de prevención de la hipertrofia vascular en la aorta torácica por un mecanismo que es independiente de la presión.

Estudios de Igase et al. ${ }^{20,36}$ en arterias de conducción, específicamente aorta y arteria carótida de ratas espontáneamente hipertensas apoyan nuestros resultados y muestran que los niveles de mRNA de ECA-2 y de proteína se asociaron con inmunoreactividad positiva para Ang-(1-7). El tratamiento de estos animales con un antagonista del RAT1 aumentó 5 veces los niveles de mRNA para ECA-2 y se asoció con un aumento significativo de los niveles aórticos de Ang-(1-7), junto con una disminución del grosor de la pared aórtica, sugiriendo que la ECA-2 podría actuar como mecanismo protector de eventos cardiovasculares durante la HTA.

Zulli et $\mathrm{al}^{37}$ han mostrado por inmunohistoquímica en aorta torácica de conejos sometidos a una dieta rica en colesterol, un aumento de la expresión de ECA-2 y del RAT2 en macrófagos y en células de la musculatura lisa de placas aterogénicas. Aunque se reconoce que la inhibición de la ECA o del RAT1 previene la ateroesclerosis ${ }^{38}$, otros mecanismos ateroprotectivos podrían ser estimulados. Al respecto, la inhibición de la ECA no sólo disminuye la formación de Ang II, sino que también aumenta la disponibilidad de Ang I para formar Ang -(1-9) vía ECA-2.

Aunque no hay estudios del rol ateroprotectivo de la Ang-(1-9). Este péptido es convertido a Ang-(1-7), el que sí presenta propiedades antiaterogénicas ${ }^{39}$. Resultados previos en modelos experimentales de remodelamiento temprano y tardio post infarto mostraron que los niveles circulantes de Ang(1-9) correlacionaron positivamente con la actividad de ECA-2 e inversamente con la actividad de ECA ${ }^{40}$.

La primera demostración de la regulación de la ECA-2 fue entregado por Ishiyama et al. ${ }^{41}$, al estudiar el papel modulador del RAT1 en los niveles del mRNA de la ECA-2 cardíaca. Se evaluó si el gen de la ECA-2 responde al aumento compensatorio en los niveles circulantes y tisulares de Ang II y Ang-(1-7), producto de la disfunción del ventrículo izquierdo (VI) post IAM. Para ello determinaron en ratas infartadas el efecto de los antagonistas del RAT1 (ARAll), losartán y/o olmesartan, durante 28 días post IAM. El mRNA para ECA-2 aumentó 3 veces en el miocardio viable y se correlacionó con los niveles de Ang-(1-7). También se encontró un aumento del mRNA de ECA-2 al usar un ARAll que inhibió tanto RAT1 y RAT2. Estos datos sugierieron que la Ang II podría ser el estímulo determinante de la expresión cardiaca de la ECA-2, ya que la disminución de los niveles de Ang II o la prevención de su unión a los RAT1 aumentó los niveles del mRNA para ECA-2. Al respecto, hemos encontrado en un modelo remodelamiento miocárdico (RM) tardío post IAM en la rata, un aumento de la actividad enzimática de la ECA y de los niveles de Ang II y una disminución de la actividad enzimática de la ECA-2 y de los niveles de Ang-(1-9) 42 $^{2}$ Estos cambios favorecieron la fibrosis miocárdica en el área no infartada y el desarrollo de hipertrofia ventricular patológica ${ }^{43}$. El bloqueo del receptor de Ang II con candesartan previno la disminución de la actividad de ECA-2, aumentó significativamente los niveles de Ang-(1-9) y disminuyó el remodelamiento ventricular en el área no infartada, además de la actividad de metaloproteasa tipo $2^{44}$. Estos resultados sugirieron una interacción entre los ejes ECA-Ang II y ECA-2-Ang(1-9) en el remodelamiento miocárdico post IAM.

En conclusión, nuestros resultados entregan los primeros antecedentes del rol del eje ECA-2Ang-(1-9) en el remodelamiento hipertensivo de la pared aórtica. La modulación de los niveles de 
Menores niveles tisulares de la enzima convertidora de angiotensina I homóloga (ECA-2) y angiotensina-(1-9) están...

ECA-2 y de Ang-(1-9) podrían constituir nuevos biomarcadores y blancos farmacológicos para el tratamiento de la HTA y sus complicaciones.

\section{Agradecimientos}

Este trabajo fue financiado por Fondecyt 1070662/ FONDAP 15010006
1. VARAGIC J, FROHLICH E. Local cardiac renninangiotensin system:Hypertension and cardiac failure. $\mathrm{J}$ Mol Cell Cardiol 2002; 34: 1435-1442

2. MULVANY MJ. Effects of angiotensin converting enzyme inhibition on vascular remodelling of resistance vessels in hypertensive patients. J Hypertens Suppl 1996; 14: 21-24.

3. DE MEY JG, SCHIFFERS PM, HILGERS RH, SANDERS $M M$. Toward functional genomics of flow-induced outward remodeling of resistance arteries. Am J Physiol Heart Circ Physiol 2005; 288: H1022-1027.

4. TOUYZ RM. Intracellular mechanisms involved in vascular remodelling of resistance arteries in 2 hypertension: role of angiotensin II. Exp Physiol 2005; 90: 449-455.

5.- JAN DANSER AH. Blood pressure-independent effects of Rho-kinase inhibitors in the kidney? J Hypertens 2004; 22 : 1675-1677.

6.- BEHR TM, WANG $X$, AIYAR N, COATNEY RW, LI X, KOSTER $P$, et al. Monocyte Chemoattractant Protein-1 is Upregulated in rats with volume-overload congestive heart failure. Circulation 2000;102:1315-1322.

7- FUNAKOSHI Y, ICHIKI T, SHIMOKAWA H, EGASHIRA $\mathrm{K}$, TAKEDA K, KAIBUCHI K, et al. Rho-kinase mediates angiotensin II induced monocyte chemoattractant protein-1 expression in rat vascular smooth muscle cells. Hypertension 2001; 38: 100-104.

8.- KOBAYASHI N, NAKANO S, MITA SI, KOBAYASHI T, HONDA T, TSUBOKOU Y, et al. Involvement of Rho-kinase phathway for angiotensin II induced plasminogen activator inhibitor-1 gene expression and cardiovascular remodeling in hypertensive rats. J Pharmacol Exp Therap 2002; 301: 459-466.

9.- TAKEDA K, ICHIKI T, TOKUNOU T, IINO N, FUJII S, KITABATAKE A, et al. Critical role of Rho-kinase and MEK/ ERK pathways for angiotensin II-induced plasminogen activator inhibitor type-1 gene expression. Arterioscler. Thromb. Vasc Biol 2001; 21: 868-873.

10. DONOGHUE M, HSIEH F, BARONAS E, GODBOUT K, GOSSELIN M, STAGLIANO N, et al. A novel angiotensinconverting enzyme-related carboxypeptidase (ACE2) converts angiotensin I to angiotensin 1-9. Circ Res 2000; 87: e1-e9.

11. TIPNIS SR, HOOPER NM, HYDE R, KARRAN E, CHRISTIE G, TURNER AJ. A human homolog of angiotensin converting enzyme. Cloning and functional expression as a captopril-insensitive cardoxypeptidase. J Biol Chem 2000; 275: 33238-33243.

12. TURNER AJ, TIPNIS SR, GUY JL, RICE G, HOOPER NM. ACEH/ACE2 is a novel mammalian metallocarboxypeptidase and a homologue of angiotensinconverting enzyme insensitive to ACE inhibitors. Can J Physiol Pharmacol 2002; 80: 346-453.

13.TURNER A, HOOPER N. The angiotensin-converting enzyme gene family: genomics and pharmacology. Sci 2002; 23:177-183.

14 CRACKOWER MA, SARAO R, OUDIT GY, YAGIL C, KOZIERADZKI I, SCANGA SE, et al. Angiotensinconverting enzyme 2 is an essential regulator of heart function. Nature 2002; 417:822-828.

15. DONOGHUE M, WAKIMOTO H, MAGUIRE CT, ACTON S, HALES P, STAGLIANO N, et al. Heart block, ventricular tachycardia, and sudden death in ACE2 transgenic mice with downregulated connexins. J Mol Cell Cardiol 2003; 35:1043-1053

16. OCARANZA MP, GODOY I, JALIL JE, VARAS $M$, COLLANTES P, PINTO $\mathrm{M}$, et al. Enalapril attenuates downregulation of Angiotensin-converting enzyme 2 in the late phase of ventricular dysfunction in myocardial infarcted rat. Hypertension 2006,48: 572-578

17. OCARANZAMP, VARAS M, GODOYI, NILO F, MACKENSIE $D, A L A R C O ́ N M$, et al. El aumento de la expresión de la enzima convertidora de angiotensina I homóloga (ECA2) inducido por enalapril se asocia a menor fibrosis e hipertrofia ventricular izquierda post infarto al miocardio en la rata. Rev Chil Cardiol 2007; 26: 63-76

18. OCARANZA MP, GODOY I, PINTO M, ROMÁN M, VARAS $\mathrm{M}$, LAVANDERO $\mathrm{S}$, et al. Improved ventricular function by blockage of the AT1 receptor is associated to increased ACE2 and higher levels of angiotensins 1-9 and 1-7 in the late remodeling post-myocardial infarction. Inter-American Society of Hypertension XVIIth Scientific sessions 2007, Miami, USA

19. OCARANZA MP, PIDDO AM, FAÚNDEZ P, LAVANDERO $S$, JALIL JE. Angiotensin l-converting enzyme gene polymorphism influences chronic hypertensive response in the rat Goldblatt model. J Hypertens 2002; 20: 413-420.

20. IGASE M, STRAWN WB, GALLAGHER PE, GEARY RL, FERRARIO CM. Angiotensin II AT1 receptors regulate ACE2 and angiotensin-(1-7) expression in the aorta of spontaneously hypertensive rats. Am J Physiol Heart Circ Physiol. 2005; 289: H1013-H1019.

21. RIVERA P, OCARANZA MP, LAVANDERO S, JALIL JE. Rho Kinase Activation and Gene Expression Related to Vascular Remodeling in Normotensive Rats With High Angiotensin I-Converting Enzyme Hypertension 2007; 50: 793-799.

22. OLIVERI C, OCARANZA MP, CAMPOS X, LAVANDERO 
S, JALIL JE. Angiotensin I-converting enzyme modulates neutral endopeptidase activity in the rat. Hypertension 2001; 38: 650-654

23. JOHNSON G, AHN K. Development of an internally quenched fluorescent substrate selective for endothelinconverting enzyme-1. Anal. Biochem 2000; 286: 112-118.

24. LAWRENCE AC, EVIN G, KLADIS A, CAMPBELL DJ. An alternative strategy for the radioimmunoassay of angiotensin peptides using amino-terminal-directed antisera: measurement of eight angiotensin peptides in human plasma. J Hypertens 1990; 8: 715-724.

25. RAKUGI H, WANG DS, DZAU VJ, PRATT RE. Potential importance of tissue angiotensin-converting enzyme inhibition in preventing neointima formation. Circulation 1994; 90: 449-455

26. RIZZONI D, PORTERI E, PICCOLI A, CASTELLANO M, BETTONI G, MUIESAN ML, et al. Effects of losartan and enalapril on small artery structure in hypertensive rats. Hypertension 1998; 32: 305-310.

27. ALLRED AJ, DIZ DI, FERRARIO CM, CHAPPELL MC. Pathways for angiotensin-(1---7) metabolism in pulmonary and renal tissues. Am J Physiol Renal Physiol. 2000; 279: F841-850

28. IYER SN, YAMADA K, DIZ DI, FERRARIO CM, CHAPPELL MC. Evidence that prostaglandins mediate the antihypertensive actions of angiotensin-(1-7) during chronic blockade of the renin-angiotensin system. J Cardiovasc Pharmacol 2000; 36: 109-117

29. SANTOS RA, SIMOES E SILVA AC, MARIC C, SILVA DM, MACHADO RP, DE BUHR I, et al. Angiotensin-(1-7) is an endogenous ligand for the $G$ protein-coupled receptor Mas. Proc Natl acad Sci 2003; 100: 8258-8263.

30. SANTOS R, FERREIRA A, NADU A. Expresión o fan angiotensin-(1-7)- producing fusion protein produces cardioprotective effects in rats. Physiol genomics 2004; 17 : 292-299.

31. YAGIL Y, YAGIL CH, CRACKOWER M, PENNINGER J. The protective role of ACE2 in hypertension. Am J Hyper 2003; 16: 23A

32. HAMMING I, TIMENS W, BULTHUIS ML, LELY AT, NAVIS GJ, VAN GH. Tissue distribution of ACE2 protein, the functional receptor for SARS coronavirus. A first step in understanding SARS pathogenesis. J Pathol 2004; 203: 631-637.

33. STRAWN WB, FERRARIO CM, TALLANT EA. Angiotensin(1-7) reduces smooth muscle growth after vascular injury. Hypertension 1999; 33: 207-211.

34. FREEMAN EJ, CHISOLM GM, FERRARIO CM, TALLANT EA. Angiotensin-(1-7) inhibits vascular smooth muscle cell growth. Hypertension 1996; 28: 104-108

35. OCARANZA MP, MOYA J, VALENZUELA J, VARAS M, JALIL JE. Menor expresión de la enzima convertidora de angiotensina homóloga ECA2 se asocia a mayor remodelamiento de pared aórtica de ratas con niveles genéticamente elevados de angiotensina II. Rev Chil Cardiol 2008; 27: 480-491.

36. IGASE M, KOHARA K, NAGAI T, MIKI T, FERRARIO CM. Increased expression of angiotensin converting enzyme 2 in conjunction with reduction of neointima by angiotensin II type 1 receptor blockade. Hypertens Res 2008; 31:553-559.

37. ZULLI A, BURRELL L WIDDOP R, BLACK MJ, BUXTON BF, HARE DL. Immunolocalization of ACE2 and AT2 receptors in rabbit atherosclerotic plaques. J Histochem Cytochem 2006; 54: 147-150

38. CECONI C, FOX KM, REMME WJ, SIMOONS ML, DECKERS JW, BERTRAND $M$, et al. ACE inhibition with perindopril and biomarkers of therosclerosis and thrombosis: results from the PERTINENT study. Atherosclerosis 2009; 204: 273-275

39. FERRARIO CM. Angiotensin-(1-7) and antihypertensive mechanism. J Nephrol 1998; 11: 278-283

40. OCARANZA MP, GODOY I, RAMIREZ C, JALIL JE. Disminución de la actividad de la ECA2 (enzima convertidora de angiotensina I homóloga) en la disfunción ventricular izquierda post infarto al miocardio en la rata. Rev Chil Cardiol 2005; 24: 83-93.

41. ISHIYAMA Y, GALLAGHER P, AVERILL E, TALLANT $A$, BROSNIHAN K, FERRARIO C. Up regulation of angiotensin-converting enzyme 2 after myocardial infarction by blockade of angiotensin II receptors. Hypertension 2004; 43: 970-976 